\title{
La traducción como género literario en el Renacimiento francés
}

\author{
Miguel Á. garcía Peinado \\ Universidad de Córdoba
}

Resumen: Trabajo que trata sobre la traducción en el siglo XVI basándose en cuatro textos fundamentales: Étienne Dolet (Maniere de bien traduire d'une langue en aultre -1540), Jacques Peletier du Mans (L'Art poétique d'Horace traduit en vers français -1541), Thomas Sébillet (Art Poëtique François, pour l'instruction des jeunes studieus, et encor peu avancez en la Poësie Françoise -1548) y Joachim Du Bellay (Deffence et Illustration de la langue françoyse -1549).

Palabras clave: Traducción, Literatura, Renacimiento, artes poéticas.

Abstract: This paper discusses the translation done in the 16th century in four fundamental texts: Étienne Dolet (Maniere de bien traduire d'une langue en aultre, 1540), Jacques Peletier du Mans (L'Art poétique d'Horace traduit en vers françcais, 1541), Thomas Sébillet (Art Poëtique François, pour l'instruction des jeunes studieus, et encor peu avancez en la Poësie Françoise, 1548) and Joachim Du Bellay (Defference et Illustration de la languae francoyse, 1549).

Key Words: Translation, Literature, Renaissance, Poetics.

\section{INTRODUCCIÓN}

En los inicios del siglo XXI es un hecho constatado, y que poco a poco va siendo aceptado, la importancia de la traducción como acontecimiento cultural de primera magnitud. Ciñéndonos al terreno literario, y más concretamente al terreno poético, ya desde la Edad Media la traducción ha asegurado la comunicación literaria entre las sociedades y civilizaciones de lenguas o idiomas diferentes. Así, aunque muy practicada por los clérigos medievales, ha gozado de una notoriedad bastante mayor en el Renacimiento como consecuencia inmediata del Humanismo ${ }^{1}$. Para que esta empresa novedosa triunfe plenamente en el siglo XVI, debe destacarse no sólo la gran ayuda de la 'gran dama de las letras' del Renacimiento, Margarita de Navarra, sino también la de su hermano el rey Francisco I (1515-1547), el cual, además de su conocida pasión por la arquitectura y la pintura, vio pronto que la traducción constituía un precioso

\footnotetext{
${ }^{1}$ Léfèvre d'Étaples (¿1450?-1536) es el primero en traducir enteramente La Biblia.
} 
medio de cultura para sus súbditos: impulsado por su hermana, por el traductor y jurista Jean Colin y por Guillaume Budé, creó en 1530 la 'trilingue et noble Académie', origen del futuro 'Collège de France', favoreciendo a los humanistas en su oposición a la tradición de La Sorbona.

Está comprobado que el rey mostró siempre gran estima por la labor traductora, animando a los que se dedicaban a ella y recompensándolos con cargos cerca del propio rey. Utilizó, incluso, la biblioteca de autores griegos que había regalado el escritor de Savoya, Claude de Seyssel (14501520) a su predecesor Luis XII, para que se llevaran a cabo traducciones de los autores. Estos 'translateurs' eran conscientes del "grand zèle du Roy à ouyr et veoir tous bons autheurs traduitz en langue françoise", como escribe uno de ellos en la dedicatoria de su trabajo; en estas 'dedicaces' todos se esfuerzan por ser los que mejor muestren su agradecimiento al rey, pudiendo ponerse como ejemplo los versos de Héroët:

Soubz vostre nom, soubz vostre bon exemple,

On peult venter ce Royaulme tresample

De n'estre moins en lettres fleurissant

Qu'on l'a congneu par guerre trespuissant.

Sur ce propos ma langue ne peult taire

Ce que vous doibt nostre langue vulgaire,

Laquelle avez en telz termes reduicte,

Que par elle est la plus grand part traduicte

De ce qu'on lict de toute discipline

En langue Grecque, Hebraïcque et Latine ${ }^{3}$.

No es extraña la alusión de Héroët a la traducción, ya que en esta época se traduce en verso la obra de los poetas clásicos. Y no sólo los 'translateurs' propiamente dichos, sino los propios poetas; éstos, no desdeñan la nueva práctica y ponen en ella el mismo interés que en sus poesías. Veamos algunos nombres y su labor traductora.

Octovien de Saint-Gelais (1468-1502): se le deben traducciones en verso francés de obras latinas; para el rey Carlos VIII, Octovien redacta en 1496 una traducción en decasílabos de las 21 epístolas amorosas

\footnotetext{
${ }^{2}$ Sobre este punto, véase la obra de Marc FumARol (dir.): Les Origines du Collège de France, Paris, 1998.

${ }^{3}$ Antoine Héroët (1492-1568), el 'digne évêque de Digne', como lo llamaba maliciosamente Valery Larbaud, vivió en el entorno de Margarita de Navarra, que lo protegió. Es considerado como uno de los mejores discípulos de la escuela de Marot y escritor muy reconocido por los humanistas. Se ocupó durante bastante tiempo de las teorías platónicas sobre el amor, exponiendo en L'Androgyne una hipótesis elevada sobre el nacimiento del amor; lo redactó en 1536 y lo publicó en 1542. Los versos citados pertenecen a la dedicatoria a Francisco I.
} 
- ficticias- de Ovidio, tituladas Heroidas ${ }^{4}$. Asimismo, una traducción de La Eneida, fechada en 1500.

Clément Marot (1496-1544): entre 1511 y 1514 traduce la Première Églogue de Las Bucólicas de Virgilio y el Jugement de Minos de Luciano. En 1534 aparece su traducción Premier Livre de la Métamorphose d'Ovide, que, junto con otras dos obras publicadas ese año, será un gran éxito de librería y lo convertirán en el 'poète-phare' de su generación. En 1539 se publica la traducción de seis sonetos de Petrarca y de Cinquante Pseaumes de David ${ }^{5}$. En varias etapas de su vida, Marot traducirá a los poetas neolatinos Salmon Macrin, Jean Visagier, Gilbert Ducher, Hubert Sussaneau, Antoine de Gouvéa y Nicolas Bourbon.

Hugues Salel (1504-1553): procedente junto con sus camaradas Marot y Olivier de Magny de la misma provincia francesa -Quercy-, es un precursor de 'la Pléïade' e imitador de Marot; su traducción de los diez primeros cantos de La lliada en versos de diez pies (1545) fue todo un acontecimiento en su tiempo. Se trata de un monumental trabajo, iniciado a petición de Francisco I, cuyos primeros cantos son publicados en 1542, convirtiendo a Salel en el traductor-poeta más célebre del momento. A partir de 1545 se publican los diez cantos, en los que Salel reivindica la gloria para su tarea de traductor, dada la dificultad de su empresa.

Olivier de Magny (1520-1561): secretario de Hugues Salel, a la muerte de éste se encargó de reunir y publicar sus obras inéditas, haciendo así aparecer en 1554 la versión de los cantos XI y XII y del comienzo del XIII de La lliada. Esta es su contribución más importante a la traducción de un poeta marcado por la influencia de su paisano Marot, de los Regrets de Du Bellay en los 176 sonetos de sus Souspirs y del lirismo de Ronsard.

Amadis Jamyn (1540-1593): toda su vida al lado de Ronsard, primero como 'page' y a partir de 1562 como secretario, adquirió una gran instrucción con el humanista Dorat. Sus trabajos en el entorno del maestro y su colaboración en La Franciade le hacen concebir la idea de acabar la traducción en verso de La lliada, comenzada por Hugues Salel; así, en 1574 , publica una traducción de los libros XII a XVI, y en 1584 aparece la traducción completa. Ese mismo año verán la luz los tres primeros libros de La Odisea, con reediciones en 1599 y 1605. Su traducción de Homero, dado

\footnotetext{
${ }^{4}$ Sobre esta traducción es digno de mención el libro de D. Thoss: Publius Ovidius Naso, Héroïdes, traduites en vers français par Octovien de Saint-Gelais, München, 1986.

${ }^{5}$ Las traducciones de Marot están casi todas incluidas en el sexto de la edición crítica de C. A. MAYER (volumen VI: Traductions, London, 1980). Los Cinquante Pseaumes de David están editados por G. DEAUX (Paris, 1995).
} 
el buen conocimiento del griego de Jamyn, es famosa por la exactitud de su estilo, ágil y fluido ${ }^{6}$.

Los poetas citados nos demuestran que la traducción, en ese tiempo, se ha convertido en un género poético, como podrían ser "la ballade", "la complainte" o "l'églogue". Se trata de un nuevo género en el que los poetas, a favor del Humanismo, se esfuerzan por contribuir a su desarrollo. Además de ellos, durante la década de los treinta, destacarán algunos escritores por sus traducciones de las obras de Cicerón: Antoine Macault ${ }^{7}$, Jean Colin ${ }^{8}$, Richard Le Blanc ${ }^{9}$ y Joachim Périon ${ }^{10}$. Veamos, a continuación, el tratamiento que le dan a la traducción cuatro de los teóricos más importantes del Renacimiento francés, en la década de los cuarenta.

\section{1. ÉtIENNE Dolet: MANIERE DE BIEN TRADUIRE D'UNE LANGUE EN AULTRE (1540) \\ Curiosa personalidad la de este hombre: filólogo, impresor, erudito, poeta y -sobre todo- humanista (1509-1546) que, debido a la influencia libre- pensadora que adquirió en sus estudios en la Universidad de Padua ${ }^{11}$, pasó}

\footnotetext{
${ }^{6}$ Sobre Homero y su influencia en el Renacimiento francés debe consultarse el trabajo de Noémie HEPP: "Homère en France au XVle siècle", Atti dell'Accademia delle scienze di Torino, vol. XCVI, 1962, pp. 389-508. Para la traducción de Salel y Jamyn,. El artículo de Isidore SILVER: "Ronsard's independance of the Salel-Jamyn translation of Homer", Bibliothèque d'Humanisme et Renaissance, XVIII, 1956, p. 37 ss. Un buen análisis de la traducción de Jamyn encontraremos en el artículo de S. M: CARRINGTON: "Jamyn, translator of Homer", French Renaissance Studies in honor of Isidore Silver (Frieda S. Brawn ed.), Kentucky Romance Quaterly, XXI, 1974, pp. 123-136.

7 Traductor y poeta, 'valet de chambre' de Francisco I, conocido con el apodo de 'Macault le gentil traduisant".

${ }^{8}$ Jurista que tradujo las obras de Plutarco y de Cicerón, asi como algunas obras del humanista español de expresión latina Juan Luis Vives

${ }_{9}^{9}$ Conocido traductor de Platón, Hesíodo, Ovidio, Cicerón, Virgilio y otros autores greco-latinos.

${ }^{10}$ Benedictino de la abadía de Cormery, que se denominaba a si mismo "traducteur du roi pour les langues hébraïque et grecque", que tradujo obras muy diversas. En 1540 plantea el problema de la traducción en De optimo genere interpretandi in decem Aristotelis Ethicorum libros.

${ }^{11}$ Por lo que concierne a los libre-pensadores (catalogados generalmente como 'libertinos), el término 'libertinage': "licence d'esprit qui rejette les croyances religieuses; état de celui qui est libertin", generalmente se localiza en el período comprendido entre 1536 y 1645; parece ser que fue Calvino el que designó por primera vez, en 1545, con el nombre de "libertins" a todos aquellos que él catalogaba como heréticos. Sin embargo, la represión sufrida por los libertinos no se sitúa en esas fechas, sino entre los años 1574 y 1662, siendo sus víctimas más conocidas las siguientes: Georges o Geoffroy Vallée, ejecutado en 1574 debido a la publicación de su obra La Béatitude des chrestiens ou le Fléo de la foix, en la que expresaba opiniones deístas; Lucilio Vanini, filósofo italiano ordenado sacerdote, que fue quemado vivo en Toulouse, en 1619, acusado de magia y de astrologia; su libro Amphitheatrum aeternae Providentiae trataba sobre la inmortalidad del alma, y Des secrets de la Nature fue censurada por La Sorbona; Jean Fontanier, llevado a la hoguera en París junto con su obra Le Trésor Inestimable, acusado de difundir teorías ateas; Claude Le Petit, apodado 'Théophile le Jeune' en recuerdo del poeta Théophile de Viau, fue llevado a la hoguera a los 23 años, en 1662, por
} 
buena parte de su vida encarcelado, siendo quemado junto con sus libros el día de su aniversario en la plaza Maubert por orden del Parlamento de París. Su inicio en las letras ocurrió como consecuencia de haber sido elegido "orateur de la Nation française et défenseur fougueux de ses prérogatives": en 1533 pronunció dos violentos discursos contra los 'Toulousaints' y su Parlamento; el hecho provocó un gran escándalo, siendo arrestado y encarcelado. En adelante, ésta será la tónica de su vida como escritor. A partir de 1540, Dolet va a convertirse en defensor de la lengua francesa; sus publicaciones alusivas a ella, ya sean traducciones u obras originales de inspiración evangelista, van a ser decisivas entre su producción; de ésta gran empresa que va a iniciar, a la que titulará Orateur françois, y que debía comprender la gramática, la ortografía, la fonética, la etimología, la traducción, la retórica y la poética, sólo publicará un fragmento: Manière de bien traduire d'une langue en aultre. D'advantage. De la Punctuation de la langue Françoyse. Plus. Des accents d'ycelle ${ }^{12}$. Dolet formula en su obrita algunas ideas novedosas, para su época claro está, reclamando el empleo del apóstrofo para así evitar los hiatos cacofónicos; aboga por las traducciones exactas en cuanto al sentido; defiende la sustitución de palabras acabadas en -ez por -és, etc. Ya en el

la publicación de Le Bordel des muses ou les neuf pucelles putains. En el siglo XVII, es preciso entender por 'libertinage' el conjunto de doctrinas, o más bien de actitudes personales, que, sobre todo en Francia, fueron propias de literatos, magistrados, políticos, filósofos y moralistas a quienes se debe la crítica de las creencias tradicionales; crítica en gran parte subterránea, pero de la que quedan abundantes vestigios en la literatura anónima o clandestina de la época. El libertinaje no es una filosofía ni un cuerpo coherente de doctrinas, sino un movimiento cultural que utiliza y hace suyos, como instrumentos de crítica o de liberación, doctrinas pertenecientes a diversos sistemas. La idea que los historiadores franceses tienen de los libertinos es tan variada como los nombres que les dan: 'libertins', 'épicuriens', 'nieurs' (ateos), 'doubteurs' (escépticos), 'deistes', 'hérétiques', 'esprits forts', etc. Todos los ensayos que tratan de definirlos son en buena parte incompletos, partiendo del defecto común de suponer que la incredulidad procede de un vicio de conciencia o de gracia individual, cuando de hecho procede de un fondo intemporal de indocilidad, que en cada época está matizado por las características inherentes a ella; así, el incrédulo del siglo XIV será averroísta u occamista; el del XVI aristotélico; el del XVIII enciclopedista y el del XIX positivista. De todos modos, entre los libertinos del XVII se puede distinguir una tradición común cuyas raices parecen remontarse al racionalismo del siglo anterior y éste al hogar de libre pensamiento mantenido desde la Edad Media en la Escuela de Padua; hay que entender por tal un movimiento filosófico y científico centrado en la citada Universidad, y que se desarrolló durante los siglos XIV, XV y XVI, caracterizado en general por desinteresarse de los problemas teológicos (al menos en el sentido en que éstos eran tratados de forma coetánea por los teólogos de La Sorbona), y por interesarse enormemente en cuestiones del conocimiento de la Naturaleza. Estas teorías fueron dadas a conocer en Francia y en Europa por Pietro Pomponazzi ("Peretto") y Lucilio Vanini.

${ }^{12}$ Opúsculo publicado en Lyon, en 1540. Existen dos ediciones modernas de Manière de bien traduire d'une langue en aultre: una de Jacques PERRIN, Genève, Slatkine Reprints, 1972; otra comentada de N. BRIAMONTE en Annali della Facoltà di lingue e lettere straniere di Ca'Foscari, t. XXI, 1-2, 1982, pp. 15-27. 
prólogo, dirigido a Guillaume de Langey, anuncia claramente su proyecto: "... régler et illustrer la langue, pour l'honneur de son pays". En el texto, Dolet daba cinco reglas para traducir correctamente, citadas con frecuencia por los antólogos, y de las que extracto las ideas fundamentales sobre la traducción:

Para traducir bien de una lengua a otra se requieren principalmente cinco cosas.

En primer lugar, es preciso que comprenda perfectamente lo que dice el autor que traduce; pues, si lo entiende, nunca será oscuro en su traducción. Y si el autor que traduce no es nada complicado, lo podrá presentar de manera fácil y completamente inteligible (...).

La segunda cosa que se requiere en la traducción es que el traductor conozca perfectamente la lengua del autor que traduce y que sea asimismo excelente en la lengua a la que traduce (...).

El tercer principio es que, al traducir, no debe uno ceñirse tanto al texto que resulte una traducción palabra por palabra o al pie de la letra. Si alguien lo hace así, es por pobreza y falta de espíritu. Porque, si posee las cualidades que acabamos de señalar (cualidades que deben darse en un buen traductor), sin preocuparse del orden de las palabras, fijará su atención en las ideas y actuará de suerte que el propósito del autor quedará expresado conservando cuidadosamente la propiedad de una y otra lengua. (...).

La cuarta regla que quiero dar aquí es más de tener en cuenta en las lenguas que no han llegado aún a la categoría de lenguas artísticas o perfectas. Doy el nombre de lenguas sin categoría aún real y reconocida de perfección y arte a lenguas como la francesa, la italiana, la española, la de Alemania, la de Inglaterra y otras lenguas vulgares. Cuando traduzcas un libro latino a una de estas lenguas (aunque sea la francesa), debes procurar no emplear palabras demasiado próximas al latín y poco empleadas hasta ahora en estas lenguas (...).

Vengamos ahora a la quinta regla que debe observar un buen traductor. Una regla de una fuerza tan grande que sin ella toda obra resulta pesada y poco agradable. $Y$ ¿qué dice esa regla?

Esa regla se refiere a la armonía del discurso: es decir, un enlace y un ritmo de las palabras con tal musicalidad que no sólo resulte agradable al ánimo, sino que también los oídos queden como extasiados y jamás se molesten por una tal armonía del lenguaje... ${ }^{13}$. ${ }^{13}$ La traducción es de Jesús Cantera y se encuentra en la obra de Miguel Ángel VEGA (ed.):
Textos clásicos de teoria de la traducción, Madrid, Ediciones Cátedra, 2004, pp. 125-128. Los 
2. JaCques PELETIER du MANS: L'ART PoÉtiQue d'HORACE TRADUIT EN VERS FRANÇAIS (1541).

A pesar de que la fecha de referencia citada comúnmente es la de 1545, la traducción del Art poétique de Horacio se publica por primera vez de manera anónima en 1541; la reedición de 1545 indicará el nombre de su traductor, Jacques Peletier du Mans (1517-1582), matemático, erudito, filólogo y poeta, tras pasar por varias universidades francesas, ávido de adquirir una cultura enciclopédica (París, Bayeux, Burdeos y Poitiers). Autodidacta y con una mente abierta a todas las innovaciones, Peletier se interesará por todas las ciencias conocidas del siglo XVI. Como filólogo, propugna una nueva concepción de la ortografía, participando en la querella iniciada por Meigret ${ }^{14}$, proponiendo a su vez un nuevo sistema gráfico en Dialogue de l'ortographe et prononciation françoese ${ }^{15}$.

La traducción del Arte poética de Horacio de Peletier introducirá en Francia un género y una expresión que marcarán las poéticas del Renacimiento. El prólogo va precedido por una apología de la lengua francesa, que servirá de inspiración a Du Bellay para su Défense y toma partido a favor no sólo de la lengua francesa, sino también de la traducción, que sustituye a las realidades del mundo latino en las referencias contemporáneas. Formada por dos partes, la primera trata de las relaciones

textos teóricos citados pertenecen a esta antologia, de la que mencionaré el nombre del traductor. El estudio más completo sobre Dolet sigue siendo el de R. COPLEY CHRISTIE: Étienne Dolet, le martyr de la Renaissance, Paris, 1886; se trata de una apasionada biografía que incluye numerosos documentos y traducciones del autor. Estos documentos han sido ampliados por Claude LONGEON en: Documents d'archives sur Étienne Dolet, Université de Saint-Étienne, 1977 y en una obra posterior: Bibliographie des œuvres d'Étienne Dolet, écrivain, éditeur et imprimeur, Genève, Droz, 1980. Son, asimismo, notables los trabajos de Glyn P. NORTON: The Ideology and Language of Translation in Renaissance France and Their Humanis Antecedents, Genève, Droz, 1984; V. WoRTH: Practising Translation in Renaissance France: the example of Étienne Dolet, Oxford, Clarendon Press, 1988; G. CoLLETED: Vie d'Étienne Dolet, ed. M. Magnien, Genève, Droz, 1992; G.-A. PEROUSE (ed.): Études sur Étienne Dolet... publiées à la mémoire de Claude Longeon, Genève, Droz, 1993.

${ }^{14}$ Louis Meigret (¿1510?-¿1560?), gramático y traductor de obras griegas y latinas: Plinio, Aristóteles, Columelo, Polibio, Isócrates, Salustio, Cicerón..., es conocido fundamentalmente por haber sostenido una de las reformas más originales de la ortografía francesa; lo esencial de su proyecto está enunciado en estas líneas: "La letre est la note de l'element, et comme quasi une façon d'image d'une voix formee (...). Et que tout ainsi que tous corps composez des elemens sont resolubles en eux, et non en plus n'y moins: Qu'aussi tous vocables sont resolubles es voix dont ilz sont composez. Parquoy il fault confesser que puis que les letres ne sont qu'images de voix, que l'escriture deura estre d'autant de letres que la prononciation requiert de voix: Et que si elle se treuue autre, elle est faulse, abusiue, et damnable (...). L'uzaje de l'ecriture branle soubs çelui de la prononçiaçion; les lęttres ont ęté inuęntees pour rapporte lęs voęs (...). II ne vous fault que la prononciation françoise, et sauoir la puissance des letres, sans vous amuser à l'orthographie des autres langues" (Traicté touchant le commun usage de l'escriture françoise (Paris, J. Longis, 1542).

${ }^{15}$ La obra ha sido reeditada por L. C. PORTER (Genève, Droz, 1966). 
del arte y de la naturaleza, de la imitación y de la tradición, en términos próximos a Quintiliano. La segunda parte, que expone una concepción patriótica del poeta, es más original; en ella, la rima y el metro, el ritmo y el género son examinados sin pedantismo ni dogmatismo alguno, el soneto es la estrofa más alabada y la obra concluye con una ética de la poesía.

La traducción de Peletier de la obra de Horacio, en verso decasílabo, aparece al término de un período particularmente activo, en el cual la abundancia de traducciones es el signo más relevante del papel creciente que representa la lengua vulgar en la cultura escrita. Entre 1475 y 1540 , trescientas sesenta y dos obras - de las cuales noventa y ocho corresponden a autores clásicos- son traducidas al francés. El período coincide con un renacer del interés por Horacio: la edición princeps de sus obras completas, aparecida en 1470 , se continúa con las obras comentadas del humanista florentino Cristóforo Landino (1482), del impresor belga Josse Bade (1502), de Giovanni Britannico (1518), de Aulus Janus Parrhasius (1531), y de Henricus Glareanus (1543).

Para centrar la cuestión de la traducción en la época es preciso aclarar que, mientras que para los humanistas el derecho de traducir era absoluto, para los teólogos debía estar sometido a una reglamentación estatutaria. Así, los teólogos veían en el lenguaje y en la traducción un misterio escriturario ${ }^{16}$ y teológico, mientras que los humanistas invocaban a Cicerón y Quintiliano defendiendo una traducción considerada como el medio más eficaz para captar el estilo y volver a encontrar el sentido del texto original.

En su Arte poética Horacio abordaba el problema de la traducción y del grado de fidelidad que ésta debe al original en los versos 131-135 de su Epístola a los Pisones:

Publica materies priuati juris erit, si non circa uilem patulumque moraberis orbem, nec uerbo uerbum curabis reddere fidus interpres nec desilies imitator in artum, unde pedem proferre pudor uetet aut operis lex.

La prestigiosa edición que ha servido de base a gran parte de los críticos y estudiosos de Horacio en el siglo XX ha sido la de François Villeneuve ( 3 vols., París, Les Belles Lettres, 1927-1934); la traducción propuesta es la siguiente:

Vous ferez d'une matière prise au domaine public votre propriété privée si vous ne vous attardez pas à faire le tour de la piste banale et

\footnotetext{
${ }^{16}$ El que hace profesión de declarar y enseñar la Sagrada Escritura, y ha adquirido grande inteligencia de la Biblia (Diccionario de la Lengua Española de la Real Academia, decimonovena edición, Madrid, 1970, p. 562).
} 
ouverte à tous, si vous ne vous appliquez pas à rendre, traducteur trop fidèle, le mot par le mot, si vous ne vous jetez pas, en imitant, dans un cadre étroit d'où la timidité ou bien l'économie de l'œuvre vous interdiront de sortir ${ }^{17}$.

Las traducciones castellanas, llevadas a cabo en prosa ${ }^{18}$, todas ellas, parecen basarse en esta edición francesa; una traducción congruente de los versos de Horacio en alejandrinos sería la siguiente:

\footnotetext{
${ }^{17}$ Me he servido de la edición de 1978 (septième tirage).

18 De las cinco que he podido consultar no hay ninguna versificada; tres de ellas están realizadas en disposición versal pero no en verso, ya que éstos no se ajustan a medida alguna; dada la brevedad de los versos de Horacio transcribo las versiones:
}

"La materia pública será de derecho privado

si no te demoras en torno al círculo vil y extendido, y no procuras palabra a palabra verter cual seguro intérprete y no bajas como imitador a lo estrecho, de do sacar el pie, el pudor o la ley de la obra prohíban."

(Horacio: Arte poética, traducción, versión rítmica y notas de Tarsicio HERRERA ZAPIÉN, Universidad Nacional Autónoma de México, 1970).

"Un tema público será de tu privado poder, si no te demoras en circunlocuciones de poca calidad y asequibles a todos, ni fiel intérprete te preocupas de traducir palabra por palabra, ni imitando te metes en un atolladero de donde el pudor o la ley de la obra te impedirán salir."

(Aristóteles, Horacio, Boileau: Poéticas, edición preparada por Aníbal GonZÁleZ PÉREZ, Madrid, Editora Nacional, 1984).

"Los argumentos de uso común serán de tu propiedad si no te entretienes en los pasajes vulgares y triviales y no te preocupas en traducir, como fiel intérprete, palabra por palabra, o no te ciñes, como un plagista, a una estricta imitación, donde la timidez o el carácter de la obra te impiden cambiar un solo pie métrico."

(Horacio: Obras completas, Introducción, traducción y notas de Alfonso CuATRECASAS, Barcelona, Planeta, 1986)

"La pública materia de tu derecho privado será,

si no te quedas dando vueltas a un ciclo vil y pateado,

ni te preocupas por reproducir palabra por palabra, cual fiel intérprete, ni te lanzas a un callejón de donde el apocamiento impida salir o la ley de la obra."

(Horacio: Sátiras. Epístolas. Arte Poética, Edición bilingüe de Horacio SILVESTRE, Madrid, Cátedra, 1996).

"La materia del dominio público será de tu propiedad,

si no te demoras en lugares comunes y triviales,

si no te preocupas por traducir, fiel intérprete,

palabra por palabra, o no te arrojas, plagiador, a un barranco,

de donde te impedirá salir la modestia o las leyes del género."

(Quinto Horacio Flaco: Epístolas. Arte poética, Edición crítica, traducción y notas de Fernando NAVARRO ANTOLÍN, Madrid, CSIC, 2002). 
Lograrás dominar cualquier asunto público,

si no pierdes el tiempo en lo vulgar y nimio,

ni buscas trasladar -cual servil traductor-

palabra por palabra, o, imitando, situarte

en un estrecho marco del que ya no saldrás.

Horacio aborda en estos cinco versos un tema trascendental en la polémica literaria de su tiempo, el de la originalidad con respecto a los temas heredados de la tradición y con respecto a los modelos; partiendo de Aristóteles, que hace de Homero un modelo por su capacidad para expresar dramáticamente la materia:

Homero es digno de alabanza por otras muchas razones, pero sobre todo por ser el único de los poetas que no ignora lo que debe hacer. Personalmente, en efecto, el poeta debe decir muy pocas cosas; pues, al hacer esto, no es imitador. Ahora bien, los demás continuamente están en escena ellos mismos, e imitan pocas cosas y pocas veces. Él, en cambio, tras un breve preámbulo, introduce al punto un varón, o una mujer, o algún otro personaje, y ninguno sin carácter, sino caracterizado. $(1460, \text { a })^{19}$.

En estos versos Horacio, traductor él mismo (o adaptador), no atacaba a los traductores, sino que únicamente describía lo que un poeta no debe hacer; así pues Horacio no habla de traducción, sino de ímitación poética, es decir, de la refundición de un texto del cual el poeta recupera desde dentro los temas y la sustancia, en lugar de limitarse a la fidelidad exterior que presta más atención a una formulación literal. Por lo que afecta a la traducción propiamente dicha, Horacio considera que la preocupación del traductor fiel debería ser la fidelidad a las palabras; de este modo, haciendo gala de un 'literalismo' prudente, pedía al traductor-filólogo que prestara atención a las respectivas especificidades de las dos lenguas en cuestión.

En el prólogo a su traducción en verso de Horacio, Peletier se apoya en la retórica y la terminología greco-latinas para enriquecer el francés y hacer de él un instrumento eficaz de traducción. Los autores latinos, ante el prestigio de la lengua griega, pusieron sus esfuerzos en 'rendre illustre' y en 'enrichir' su propia lengua, al tiempo que creaban una literatura nacional.

19 De la Poética de Aristóteles son recomendables las dos ediciones siguientes: Aristóteles: Poética, traducción, prólogo y notas de Francisco de P. SAMARANCH, Madrid, Aguilar, 1972; Aristóteles: Poética, edición trilingüe de Valentín GARCIA YEBRA, Madrid, Gredos, 1974 (cito de ésta). El texto considerado unánimemente como el mejor es el de R. KASSEL, publicado en la colección de clásicos grecolatinos de la Oxford University Press. Los números al margen son los de las páginas de la edición de Immanuel BEKKER; las letras a y $b$ representan las columnas de cada página. Es una convención admitida internacionalmente el citar a Aristóteles con esta numeración. 
Del mismo modo había ocurrido con Dante, Petrarca, Boccaccio y Sannazaro, grandes latinistas todos ellos, que habian obrado igual con la lengua 'toscana'. Un hombre de cultura enciclopédica, como era Peletier, captó inmediatamente el interés por la figura del autor latino: por mediación de Horacio, Peletier trata de dar a Francia un Arte Poética y lleva a cabo en su traducción el mismo tipo de transformación: su traducción consta de cuatrocientos setenta y seis versos de los trescientos cincuenta y seis del original, siendo para ello consciente de que contiene numerosos anacronismos, así buscados por el traductor ${ }^{20}$. Asi por ejemplo, los versos 53-58:

...Quid autem

Caecilio Plautoque dabit Romanus, ademptum

Vergilio Varioque? Ego cur, adquirere pauca

si possum, inuideor, cum lingua Catonis et Enni

sermonem patrium ditauerit et noua rerum

nomina protulerit?,

son traducidos por la siguiente estrofa:

Mais en ceci peut on fauorizer

Alain \& Mun, \& qu'un pareil credit

Soit a Marot \& Merlin (sic) interdit?

Et si ie puis feindre comme les uieux,

Pourquoi est on dessus moi enuieux,

Veu que Cretin \& lan le Maire on faiot

Notre Francois plus riche \& plus parfait,

Et nouueauz motz sur les choses ont mis?

\footnotetext{
${ }^{20}$ El titulo completo de la edición que firma Peletier como suya es: L'Art Poetique d'Horace, traduit en Vers Francois, par lacques Peletier du Mans, recongnu par l'auteur depuis la premiere impression. Moins \& meilleur. Imprimé a Paris par Michel de Vascosan, au mois d'Aoust. M. D. XLV. in-8, p. 8 verso-9 recto; facsímil ed., Paris, Aquila, 1970. La edición más reciente es la de F. Goyet, en Traités de poétique et de rhétorique de la Renaissance (Paris, UGE, 1990), ya que la de A. Boulanger (Paris, Les Belles Lettres, 1930; reimpresión: Genève, Slatkine Reprints, 1971) se refiere a L'Art Poëtique del propio Peletier de 1555, y no a la traducción de Horacio.

Puntos de vista interesantes aportan los trabajos de: Paul Chavy: "Les traductions humanistes du début de la Renaissance française: traductions médiévales, traductions modernes", Canadian Review of Comparative Literature, $\mathrm{n}^{\circ} 7,1981$; R. J. Fink: "Une Deffence et Illustration de la langue française avant la lettre: la traduction par Jacques Peletier du Mans de l'Art poétique d'Horace (1541), Canadian Review of Comparative Literature, $n^{\circ} 7,1981$; asimismo, el ya citado de Glyn P. Norton: The Ideology and Language of Translation in Renaissance France and Their Humanist Antecedents, Genève, Droz, 1984.
} 
En lugar de los poetas latinos que han bebido en las fuentes griegas (Virgilio,Vario Rufo, Plauto, Catón y Ennio), el traductor describe un Parnaso francés, formado por Alain Chartier, Jean de Meung, Clément Marot, Mellin de Saint-Gelais, Guillaume Crétin y Jean Lemaire de Belges. Esta 'recontextualización' cambia profundamente el estatus poético y retórico de la primera persona, que en el original era Horacio; Peletier se convierte en su doble y se implica en el enriquecimiento de la lengua nacional francesa.

3. Thomas Sebillet: ARt poëtique Françols, pour l'INSTRUCtion des JEUNES STUDIEUS, ET ENCOR PEU AVANCEZ EN LA POËSIE FRANÇOISE (1548).

En el prólogo a su Orateur français declaraba Dolet su intención de publicar, en el plazo de dos o tres años, un Art poétique que estaba redactando. Esta obra, nunca publicada, habria sido la primera poética francesa del Renacimiento, ya que aunque el término aparezca por vez primera en 1541 en la traducción que Peletier propone de Horacio, habrá que esperar hasta 1548, año en que Thomas Sebillet escribe un tratado francés de poesía que inaugurará el género en Francia. Aclaremos que la expresión art poétique designaba un tratado en el que se resumían los principios de la poesía, las leyes del género que ella inspira y las reglas generales de la versificación. Hasta el momento en que aparece la obra de Sebillet, esta materia estaba incluida en los tratados medievales denominados arts de seconde rhétorique.

Thomas Sébillet (1512-1589), abogado de profesión y muy relacionado con eminentes humanistas -Michel de L'Hospital, Étienne Pasquier y Pierre de l'Estoile-, era un gran amante de la poesía y de la 'version', campo al que dedicaría buena parte de su tiempo traduciendo entre otras obras Iphigénie de Eurípides y La Vie d'Apollonios de Tyane de Filostrato. De manera anónima hizo imprimir, en 1548, su trabajo fundamental: Art Poëtique François, pour l'instruction des jeunes studieus, et encor peu avancez en la Poësie Françoise. El éxito de la obra fue tal que debió reimprimirse seis veces durante el tercer cuarto del siglo (1551, 1555, $1556,1564,1573$ y 1576$)^{21}$.

Con frecuencia se ha visto la obra como un simple tratado de la poesía de la vieja escuela, representada sobre todo por Marot; no obstante,

\footnotetext{
${ }^{21}$ La edición original se publica en París, Gilles Corrozet; las ediciones modernas son de F. GAIFFE (Paris, Cornély, 1910 -repr. 1932) y F. GOYET (Paris, 1988 y en sus Traités de poétique et de rhétorique de la Renaissance, Paris, UGE, 1990). Entre los estudios más relevantes citemos los H. de Noo: Thomas Sébillet et son Art Poëtique Françoys rapproché de la Deffence et Illustration de la Langue Françoyse de Joachim du Bellay, Utrech, 1927. Más recientemente: E AHMED: "Du Bellay, Sébillet, and the problematic identity of the French humanist", Neophilologus, LXXV, 1991 (pp. 185-193); J. VIGNES: "De l'Autorité à l'innutrition: Sébillet et Du Bellay, lecteurs de Cicéron", L'Autorité de Cicéron de l'Antiquité au XVIIle siècle, dir. J.-P. NÉRAUDAU, Orléans, Paradigme, 1993 (pp. 79-92).
} 
junto a observaciones métricas sobre los géneros tradicionales, hallamos numerosos elementos propios del ideal renacentista. Distribuida en dos libros, en el primero se ocupa de problemas generales de poesía, para tratar en el segundo de la teoría de los géneros. Es de resaltar que el autor dedica un capítulo (II, 14) a la traducción, haciendo de ella una encendida alabanza, ya que según él proporciona al autor la misma gloria que la creación original:

La version ou la traduction est aujourd'huy le poëme plus fréquent et mieus receu dés estimés poëtes et des doctes lecteurs, à cause que chacun d'eus estime grand œuvre et de grand pris, rendre la pure et argentine invention dés poëtes dorée et enrichie de notre langue. Et vrayement celuy et son œuvre méritent grande louenge, qui a peu proprement et naïvement exprimer en son langage ce qu'un autre avoit mieus escrit au sien, après l'avoir bien conceu en son esperit. Et luy est deue la mesme gloire qu'emporte celuy qui par son labeur et longue peine tire des entrailles de la terre le thrésor caché, pour le faire commun à l'usage de tous les hommes. Glorieus donc est le labeur de tant de gens de bien qui tous les jours s'y emploient: honnorable aussy sera le tien quand t'aviendra de l'entreprendre ${ }^{22}$.

\section{JOACHIM DU BELLAY: DEFFENCE ET ILLUSTRATION DE LA LANGUE FRANÇOYSE (1549).}

La aparición de la obra de Sébillet, en junio de 1548, causará una gran contrariedad a los alumnos del colegio de Coqueret ${ }^{23}$, los cuales estimaban que debían ser ellos los primeros en tener el honor de definir la poesía como un arte independiente; de ahi que el ardiente manifiesto de Du Bellay apareciera diez meses más tarde, 1549, de la de Sébillet con un programa muy concreto que comprendía tres fines esenciales: a) el triunfo definitivo de una lengua nacional, b) el advenimiento de una nueva poética,

\footnotetext{
${ }^{22}$ La traducción del texto de Sébillet (de Claude de Freyssinet) podemos hallarla en la antología citada: Textos clásicos de teoria de la traducción (pp. 129-130): "Sin embargo, te advierto que la versión o traducción de un poema es hoy en día la obra más frecuente y mejor acogida por los poetas y doctos lectores, porque todos consideran como obra de gran precio y valor el restituir la pura y argentina invención de los poetas con el oro y la riqueza de nuestra lengua. $Y$ merece grandes elogios, además de su obra, aquel que ha podido expresar limpia y llanamente en su lengua lo que otro había escrito mejor en la suya, después de haberlo concebido en su mente. Merece la misma gloria que el que, con su labor y largas penas, saca de las entrañas de la tierra el tesoro oculto, para hacerlo común al uso de todos los hombres.

Gloriosa es, pues, la labor de tanta gente de bien que todos los días se dedica a ella: y honrosa deberá ser la tuya si alguna vez se te ocurre emprenderla."

${ }_{23}$ Situado en la montaña de 'Sainte-Geneviève', en París, el colegio habia sido fundado en 1418 por Nicolas Coqueret; a principios del XVI a Denys Lefèvre, que enseñó griego y elocuencia latina, siendo uno de los impulsores del Humanismo. En la época que nos ocupa, el 'principal' del colegio era el humanista Jean Dorat.
} 
c) la fe en la alta misión del arte. A pesar de su amplitud de miras, es sorprendente la escasez de nociones teóricas, ya que la mayor parte del texto está compuesto por reflexiones lingüísticas sobre la necesidad de mejorar la lengua francesa ${ }^{24}$. Dividida la obra en dos libros, con doce capítulos cada uno, interesan a nuestro estudio los capítulos V: "Que les Traductions ne sont suffisantes pour donner perfection à la Langue Francoyse" y VI: "Des mauvais Traducteurs, \& de ne traduire les Poëtes"; veamos el razonamiento de Du Bellay:

\section{Chapitre V}

Toustefois ce tant louable labeur de traduyre ne me semble moyen unique \& suffisant, pour elever nostre vulgaire à l'egal \& parangon des autres plus fameuses Langues ${ }^{25}$. Ce que je pretens prouver si clerement, que nul n'y vouldra (ce croy je) contredire, s'il n'est manifeste calumniateur de la verité. Et premier, c'est une chose accordée entre tous les meilleurs aucteurs de rethorique, l'eloquution, la disposition, la memoire \& la pronuntiation. Or pour autant que ces deux dernieres ne se aprennent tant par le benefice des Langues, comme elles sont données à chacun selon la felicité de sa nature, augmentée \& entretenues par studieux exercice \& continuelle diligence (...) II fault donques necessairement que ces deux Langues soint entendues de celuy qui veut acquerir cete copie \& richesse d'invention, premiere \& principale piece du harnoys de l'orateur. Et quand à ce poinct, les fideles traducteurs peuvent grandement servir \& soulaiger ceux qui n'ont le moyen unique de vacquer aux Langues estrangeres (...) Voyla en bref les raisons qui m'ont fait penser que l'office \& diligence des traducteurs, autrement fort utile pour instruyre les ingnorans des Langues etrangeres en la congnoissance des choses, n'est suffisante pour donner à la nostre ceste perfection, \&, comme font les peintres à leurs tableaux, ceste derniere main que nous desirons... ${ }^{26}$

\footnotetext{
${ }^{24}$ El mejor editor de la obra, el especialista en 'la Pléiade' Henry Chamard, aclara en su "Avertissement" como un estudioso de la obra, Pierre Villey: "a montré que l'auteur de la Deffence avait traduit de l'italien à peu près tous les arguments qui constituaient son plaidoyer pour le français, et qu'une simple transposition lui avait permis de faire servir à l'apologie de son 'vulgaire' ce que Sperone Speroni, dans son Dialogue des Langues (1542), avait dit en faveur du sien contre les prétentions d'un latin tyrannique" (Joachim Du Bellay: La Deffence et Illustration de la Langue Francoyse, edición crítica de Henry Chamard, Paris, Librairie Marcel Didier, 1948 -troisième tirage, 1966, pág. VI, cito de esta edición).

${ }^{25}$ En lo concerniente a las ideas de Du Bellay sobre la traducción como medio de ilustración de la lengua nacional, y en la batalla que entabla contra Sébillet y los 'marotiques', grandes partidarios de la versión, el propio Chamard recomienda las páginas 185-188 del primero de los cuatro volúmenes de su Histoire de la Pléiade, Paris, Didier, 1930-1940.

26 "La labor tan elogiable de traducir no me parece, sin embargo, el único medio posible para elevar nuestra lengua vernácula a la altura de las lenguas más famosas y sin parangón; lo que
} 


\section{Chapitre VI}

Mais que diray-je d'aucuns, vrayement mieux dignes d'estre appellés traditeurs que traducteurs? Veu qu'ilz trahissent ceux qu'ilz entreprennent exposer, les frustrant de leur gloire, \& par mesme moyen seduysent les lecteurs ignorans, leur montrant le blanc pour le noyr: qui, pour acquerir le nom de scavans, traduysent à credict les Langues, dont jamais ilz n'ont entendu les premiers elementz, comme l'Hébraique \& la Grecque: \& encor' pour myeux se faire valoir, se prennent aux poëtes, genre d'aucteurs certes auquel, si je scavoy' ou vouloy' traduyre, je m'adroisseroy' aussi peu (...) Celuy donques qui voudra faire œuvre digne de prix en son vulgaire, laisse ce labeur de traduyre, principalement les poëtes, à ceux qui de chose laborieuse \& peu profitable, j'ose dire encor' inutile, voyre pernicieuse à l'accroissement de leur Langue, emportent à bon droit plus de molestie que de gloyre ${ }^{27}$.

\section{CONCLUSIÓN}

En 1555 Peletier publica su propia Art poétique; la insistencia, como humanista que es, en conciliar corrección filológica y fidelidad de la traducción quizás incida en el carácter propio (propietas) de cada lengua en concreto. Peletier piensa en la traducción en términos de identidad: al tener

pretendo probar tan claramente que nadie querrá - así lo espero- contradecirlo, a no ser un manifiesto calumniador de la verdad. Primero, todos los mejores autores de retórica están de acuerdo en que hay cinco partes de buen decir: la invención, la elocución, la disposición, la memoria y la pronunciación. Ahora bien, en lo que respecta a las dos últimas, éstas no se aprenden gracias al beneficio de las lenguas, ya que son dadas a cada uno según la suerte de su naturaleza y aumentadas y conservadas mediante el estudioso ejercicio y la continua diligencia (...) Por tanto, aquel que quiera adquirir la abundancia y la riqueza de la invención, primera y principal pieza del arnés del orador, será preciso que entienda estas dos lenguas. En este punto, los traductores fieles pueden prestar un gran servicio y aliviar a quienes carecen del único medio para llegar a las lenguas extranjeras (...) He aquí brevemente las razones que me han inducido a pensar que el oficio y la diligencia de los traductores, muy útil para instruir a los ignorantes de las lenguas extranjeras en el conocimiento de las cosas, no es suficiente para dar a la nuestra esta perfección, $y$, como hacen los pintores en sus cuadros, es la última pincelada la que deseamos..."

27 "¿Y qué diré de algunos, verdaderamente más dignos de ser llamados traidores que traductores? Dado que traicionan a quienes pretenden expresar, les quitan la gloria y por el mismo medio seducen a los lectores ignorantes, dándoles blanco por negro; ellos que, para adquirir el nombre de sabios, traducen sin seriedad algunas lenguas de las que nunca han oído los primeros elementos, como la hebrea o la griega, e incluso para hacerse valer, se ocupan de los poetas, una clase de autores a la que -si yo supiera o quisiera traducir- me dirigiria lo menos posible (...) Aquellos que deseen hacer una obra digna en su lengua vulgar, que dejen la labor de traducir, principalmente a los poetas, a aquellos que de modo laborioso y con poco beneficio - me atrevo a decir incluso inútilmente y con daño propio-- quieren enriquecer su lengua, con lo que, a pesar de todo, consiguen más pena que gloria." (La traducción de los párrafos seleccionados en los capitulos cinco y seis, es de Julia SEVILLA en la antologia de textos de traducción). 
las lenguas, como los pueblos, rasgos que les son propios, la asimilación de un texto por otro depende en un primer momento de la percepción que el análisis filológico procure al traductor del texto original. Las matizaciones que Peletier realiza en 1555 de los versos en cuestión ${ }^{28}$ constituyen una puesta en práctica de lo que él entiende por 'traducción fiel'; es decir, que se basa en una filología rigurosa para volver a encontrar el sentido del texto original. Digamos que en el curso de este proceso se hace patente una curiosa paradoja: para Peletier la lengua de la traducción expresa tanto más profundamente su identidad (es decir su diferencia con relación al original) cuanto más fiel es en su restitución. Cuando ese deseo llega a conseguirse, la traducción se convierte en una obra literaria.

Su Art poëtique contribuyó a elaborar las líneas maestras de 'la Pléiade', atenuando los excesos polémicos de Du Bellay y expresando "l'opinion d'une Pléiade assagie", limitando la imitación y reivindicando la creatividad del poeta. Ronsard y Du Bellay generalmente estuvieron influenciados por aquél que había presentido el lugar preponderante que debía ocupar la lengua francesa en la poesía del XVI. Durante la segunda mitad del siglo la actividad de los traductores experimentará una merma considerable, siendo pocos los casos de humanistas que se dediquen a esta tarea, recogiendo el guante de Dolet, Sébillet y Peletier; entre los pocos que lo hacen, son conocidos los nombres de Vigenère ${ }^{29}$, Le Roy ${ }^{30}$, y fundamentalmente $\mathrm{Amiot}^{31}$. La rareza de las traducciones en verso es prueba de este retroceso, algo insospechado si pensamos en las bases teóricas que se habían ido levantando durante las primeras décadas del siglo.

\footnotetext{
${ }^{28}$ Podemos hallar la traducción del párrafo concreto en la antología citada, traducido por Claude DE FREYSSINET: "Y no acabo de asombrarme de los que, para censurar la traducción palabra por palabra, se atienen a la autoridad de Horacio, cuando dice Nec verbum verbo curabis reddere, fidus Interpres, y donde Horacio dice exactamente lo contrario. Su propósito no es de traducciones (no dio preceptos sobre el asunto, por ser cosa de escaso interés para él), sino de Poética: dice que después de haber elegido una materia pública en un autor, la haremos nuestra si, entre otras cosas, no nos limitamos a restituir el pasaje palabra por palabra, como lo haría un fiel traductor." (p. 135).

${ }_{29}$ Blaise de Vigenère (1523-1596) humanista, prosista y traductor prolífico, emprendió desde 1570 la redacción de traducciones anotadas y comentadas profusamente, defendiendo en sus prólogos la traducción como un arte.

${ }_{30}$ Loys Le Roy (1510-1577), más conocido en su faceta de traductor que en la de filósofo o historiador, se elaboró una gran reputación con traducciones de Platón.

${ }^{31}$ Jacques Amyot (1513-1593) fue un gran erudito y vulgarizador en el campo de la traducción, traduciendo directamente del griego y corrigiendo sin parar sus traducciones. Fue considerado el equivalente a Ronsard en la prosa.
} 